\title{
The estimation of time as a function of positive, neutral, or negative expectancies
}

\author{
ED M. EDMONDS, DELWIN CAHOON, and BRUCE BRIDGES \\ Augusta College, Augusta, Georgia 30904
}

\begin{abstract}
Positive, neutral, and negative expectancy conditions were varied to determine their effects on time perception. Subjects were led to believe that their participation would result in a "pleasant," an "unpleasant," or a subjectively neutral experience. Intervals of 60 and 240 sec were estimated under each expectancy condition. The results indicated that the positive expectancy group tended to overestimate the actual interval (time passed relatively slowly), whereas the neutral and negative expectancy groups tended to underestimate the actual interval. The results are related to theories of time perception.
\end{abstract}

Estimation of the passage of time under various experimental conditions has been extensively investigated. While it is obvious that subjective time is often different from objective time, the reasons for this distortion are less clear. Proponents of "filled-interval" theories suggest that time estimation is a function of the number and variety of events occurring during the interval. For example, Fraisse (1963) asserts that the perception of an interval of given length is increased (overestimated) as the number and uniformity of events occurring during the interval are increased. Similarly, Ornstein (1969) proposes that as storage of the number and/or complexity of events is increased, the perceived time interval is also increased (overestimated). A different but not necessarily incompatible model is presented by those who support "expectancy" theories. For example, Filer and Meals (1949) found that subjects who anticipated a desirable goal tended to overestimate the passage of time compared with a less highly motivated control group. Cahoon and Edmonds (1980) conducted an experiment within an expectancy framework by literally creating a "watched-pot" situation. Subjects who were instructed to call the experimenter when a pot of water began boiling (the expectancy group) significantly overestimated the passage of time compared with a nonexpectancy control group. Of course, the results of the experiments based upon expectancy may also be viewed in terms of increased sensory input due to heightened attention resulting in more events perceived during the interval. Also, if expectancy is interpreted as referring to cognitive events, perhaps these events may fill intervals in the same manner as external stimuli.

The purpose of the present experiment was to compare the effects of positive and negative expectations with respect to time estimation. While the experiment is formulated within an expectancy model of time estimation, it is also relevant to a differentiation between expectancy and filled-interval theories. That is, if it is assumed that positive and negative cognitions fill inter- vals equally well, no difference in time estimation would be predicted by the filled-interval theory. However, any significant difference obtained would be compatible with the expectancy hypothesis, although the direction of the difference cannot be predicted.

\section{METHOD}

\section{Subjects}

Sixty undergraduate students enrolled in an introductory psychology course at Augusta College were randomly assigned to one of three expectancy conditions, each of which involved two levels of interval duration to be estimated.

\section{Procedure}

Upon arrival at the experimental area, each subject was given the following printed message: "The research in which you have agreed to participate will involve a personal emotional reaction. We are required by the Council on Human Experimentation to inform you that the subjective effects of your experience will be perceived as [unpleasant, neutral, or pleasant]. You may be assured, however, that under no circumstances will physical harm or long-range discomfort result from your participation."

Based upon which adjective appeared on the form (unpleasant, neutral, or pleasant), 20 subjects were assigned to each of the three expectancy conditions. These groups, in turn, were divided into groups of 10 subjects, each exposed to either a 60 - or a 240 -sec time interval. Before the experiment began, the subjects were instructed to remove metal objects from their persons (in order to insure that a watch would not be available). The subjects were then assigned to individual carrels in a study area, where they were asked to wait quietly until the "experiment" was ready to begin. Actually, a time interval of 60 or $240 \mathrm{sec}$ was monitored for each subject. At the end of this period, the subject was asked to record, in seconds, his estimate of the interval between entering the carrel and being interrupted. Paper and pencil were provided for this purpose.

\section{RESULTS AND DISCUSSION}

Table 1 shows the mean deviation times for the 60 . and 240-sec groups for each expectancy condition. Except for the overestimation for positive expectancy at the 60 -sec level, all judgments were underestimates 
Table 1

Number of Seconds Over- or Underestimated for a $60-\mathrm{Sec}$ and a 240-Sec Interval Under Positive, Neutral, and Negative Expectancy Conditions

\begin{tabular}{|c|c|c|c|c|c|c|}
\hline \multirow{3}{*}{$\begin{array}{l}\text { Inter- } \\
\text { val }\end{array}$} & \multicolumn{6}{|c|}{ Expectancy } \\
\hline & \multicolumn{2}{|c|}{ Positive } & \multicolumn{2}{|c|}{ Neutral } & \multicolumn{2}{|c|}{ Negative } \\
\hline & Mean & $\mathrm{SD}$ & Mean & SD & Mean & SD \\
\hline $\begin{array}{r}60 \\
240\end{array}$ & $\begin{array}{l}+8.5 \\
-1.5\end{array}$ & $\begin{array}{l}18.86 \\
58.61\end{array}$ & $\begin{array}{l}-18.50 \\
-35.00\end{array}$ & $\begin{array}{l}15.13 \\
57.31\end{array}$ & $\begin{array}{l}-22.50 \\
-29.00\end{array}$ & $\begin{array}{l}17.36 \\
51.45\end{array}$ \\
\hline Mean & +3.5 & & -26.75 & & -25.75 & \\
\hline
\end{tabular}

Note $-N=60$.

(time passed relatively quickly). An analysis of variance based on the differences between the actual and estimated times indicated that the expectancy main effect was significant $[F(2,54)=3.32, p<.05]$. This effect can be accounted for in terms of the differences between the positive expectancy condition and the neutral expectancy condition $[\mathrm{t}(38)=2.32, \mathrm{p}<.05]$ and between the positive expectancy condition and the negative expectancy condition $[\mathrm{t}(38)=2.29, \mathrm{p}<.05]$. The time main effect and the interaction effect were nonsignificant.

The results of this experiment are consistent with other research indicating that time duration is overestimated under expectancy or filled-interval conditions (Cahoon \& Edmonds, 1980; Fraisse, 1963; Ornstein, 1969). More specifically, the results support those of
Filer and Meals (1949), who found that subjects who anticipated a desirable goal overestimated the passage of time relative to a less motivated control condition. Finally, the results seem to confirm the commonsense impression that time passes more slowly with positive expectations (e.g., a child anticipating Christmas) than with negative expectations (e.g., a student fearful of a forthcoming examination). Whether or not the experiment supports an expectancy theory rather than a filledinterval theory is far from conclusive. However, the expectancy theory would seem to be more comprehensive, in that filled-interval theories do not imply a differential effect at tributable to positive or negative cognitive events.

\section{REFERENCES}

CAhoon, D., \& Edmonds, E. M. The watched pot still won't boil: Expectancy as a variable in estimating the passage of time. Bulletin of the Psychonomic Society, 1980, 16, 115-116.

Filer, R., \& MEALS, D. The effect of motivating conditions on the estimation of time. Journal of Experimental Psychology, $1949,39,327-331$.

Fraisse, P. The psychology of time. New York: Harper \& Row, 1963.

Ornstein, R. E. On the experience of time. London: Penguin, 1969.

(Received for publication May 25, 1981.) 